\title{
APRESENTAÇÃO: A INTERNACIONALIZAÇÃO DA PRODUÇÃO CIENTÍFICA ANGOLANA, PERSPECTIVAS E DESAFIOS
}

\author{
Eurico Wongo Gungula ${ }^{1}$ \\ https://orcid.org/0000-0002-5685-1328
}

A presente edição da revista SAPIENTIAE é desenvolvida num contexto de tamanha satisfação, em função da sua inserção na Rede de Revistas Científicas da América Latina e Caribe, Espanha e Portugal (Redalyc), constituindo-se na primeira e única revista científica africana, até ao momento, a ser integrada na referida rede, facto que revela o compromisso do seu conselho editorial, em cumprir cada vez mais com parâmetros internacionais que elevem a sua credibilidade.

Com o mesmo júbilo, temos a honra de comunicar à comunidade científica nacional e internacional que, actualmente, a SAPIENTIAE está entre as poucas revistas científicas angolanas que utilizam o Identificador de Objecto Digital (DOI), uma solução tecnológica que possibilita a identificação automática de qualquer documento disponível na Internet, aspecto que aumentará, cada vez mais, a visibilidade internacional dos artigos publicados nesta revista.

Não é segredo que a produção científica de Angola, por milhão de habitantes, continua a ser muito baixa, de acordo com o relatório sobre a ciência da Organização das Nações Unidas para a Educação, Ciência e Cultura (UNESCO, 2015), assim como as intenções do Governo de Angola, de posicionar pelo menos duas (2) Instituições de Ensino Superior (IES) no ranking académico das cem (100) melhores IES africanas, nos próximos anos.

Para que se obtenham os resultados desejados, uma das alternativas fundamentais consiste na activação de um financiamento estratégico, transparente e inadiável, que viabilize a concatenação dos processos substantivos da universidade contemporânea - educação, investigação, extensão e internacionalização - considerando que a dificuldade de estimular a produção e a publicação científica de investigadores angolanos em meios de prestigio internacional constitui, actualmente, um desafio que requer de sinergias de distintas Instituições de Ensino Superior, de Investigação e Desenvolvimento Tecnológico angolanas.

Neste sentido, os artigos seleccionados para o volume 6-1, são compostos por temas variados, nacionais e internacionais. O primeiro deles refere-se a "Enfoques predominantes no desenvolvimento comunitário em América Latina entre 2009 e 2019”, elaborado por Luis Ernesto Paz Enrique e Annia Martínez Massip, com o objectivo de descrever o enfoque rural e agrário no desenvolvimento comunitário na América Latina, no período compreendido entre 2009 e 2019. Para a obtenção de resultados foram utilizados métodos de níveis teóricos e empíricos, fundamentalmente o método bibliométrico. Foram analisados um total de 1006 artigos científicos publicados em revistas indexadas na base de dados SciELO Citation Index.

O segundo refere-se a um "Estudo sobre a influência dos factores psico-sociais na prática dos crimes no Bairro Rocha Pinto", elaborado por Domingos Bombo Damião, com o propósito de analisar os factores psico-sociais que se associam na prática dos crimes no Bairro Rocha Pinto, em Luanda-Angola. Os resultados obtidos indicam que as diferenças individuais, tais como a personalidade, desagregação familiar, a frustração, carências de sentimentos afectivos e morais, a desorganização social, problemas de auto-estima e outros mecanismos internos e instintivos do indivíduo, são factores que influenciam a prática de crimes.

O terceiro é uma abordagem sobre o "Uso das equações generalizadas de Pitzer para avaliação termodinâmica de gases", elaborada por Alfredo Muachia; Anatalísio Manuel; Jane Marques; Maria Lemos e António Chivanga Barros, com o objectivo de avaliar o comportamento

${ }^{1}$ Universidade Óscar Ribas, Angola. Email: euricowongowongo@gmail.com 
do factor de compressibilidade ( $\mathrm{Zi}$ ) de gases, em função da pressão e da temperatura, baseado num estudo numérico realizado a partir de um programa computacional, desenvolvido em linguagem $\mathrm{C}++$, que usa a equação generalizada de Pitzer. Os resultados obtidos indicam que o comportamento termodinâmico dos gases tem relação directa com o tipo e as características do gás avaliado.

O quarto é um documento sobre "Trabalhadores em movimento: do sindicalismo tradicional à acção colectiva”, elaborado por Ernesto Sánchez Sánchez e Renato Pintor Sandoval, com o propósito de analisar, desde um olhar latino-americano e a partir do contexto laboral, as novas relações que guardam o trabalhador e suas formas contemporâneas de organização, negociação e reivindicação. Neste documento é possível observar o cenário laboral-productivoorganizacional, dinamizando os mercados globais entre si, facilitando as formas de inserção laboral e comercialização da produção.

O quinto é um ensaio intitulado "construindo sentidos sobre o cuidado em saúde à luz da hermenêutica Gadameriana”, elaborado por Romano Deluque Júnior e Márcio Luís Costa, que traz uma discussão teórica sobre a construção de uma abordagem que gera novos sentidos para o tema do cuidado em saúde, à luz da Hermenêutica Filosófica de Hans-Georg Gadamer. Para tal, foram utilizados textos do próprio Gadamer (1997; 2002; 2011), assim como publicações de autores que trabalham a temática a partir do mesmo marco teórico.

O sexto é uma abordagem sobre "A gestão documental com base na governança da informação. O caso da Universidade Central "Marta Abreu” de Las Villas", feita por Asleni Díaz Jiménez e Arlene González Pérez, enfatizando que a gestão da informação proporciona a qualquer entidade universitária, uma óptima gestão de todos os seus processos.

O sétimo é uma reflexão sobre a "Viabilidade financeira na produção de micro-organismos benéficos para o tratamento de resíduos orgânicos: caso Azogues - Equador”, feita por Jorge Oswaldo Quevedo Vázquez; Lesi Vanessa Giler Escandón; Manuel Salvador Álvarez Vera e Jorge Edwin Ormaza Andrade, com o objectivo de examinar a viabilidade financeira de um projecto dirigido à produção de microrganismos que beneficiam famílias na cidade de Azogues-Equador, reduzindo vários problemas gerados pelo resíduo orgânico.

O oitavo é um "Simulacro Odontopediátrico com recurso à estratégia de ensino roleplaying em educação para a saúde oral, " feito por Maria Do Rosário Dias; Ana Brígida Antunes; Ana Rita Dias; Beatriz Duarte e Maria Calejo Pires, com o objectivo de desmistificar no âmbito de um acto pedagógico, i) o acontecimento desenvolvimentista da erupção dos dentes definitivos na criança; ii) sedimentar precocemente hábitos salutogénicos; e iii) elaborar instrumentos de Educação para a Saúde, evidenciando-se, assim, a importância da comunicação relacional e terapêutica no setting terapêutico de Medicina Dentária. É consentâneo que o roleplaying, enquanto estratégia de ensino-aprendizagem, permite que os discentes edifiquem conhecimentos sobre as suas (auto) capacidades comunicacionais, a partir de uma reflexão crítica das suas próprias experiências e/ou dos seus pares.

O nono é um documento sobre "O Bayesianismo: do casuístico ao histórico" elaborado por Milton Enrique Quero-Virla, com a finalidade de contribuir para melhorar a compreensão histórica e a definição integradora dos principais componentes da epistemologia Bayesiana.

O décimo é um documento resultante da segunda parte de uma entrevista sobre "Engenharia Epistêmica" realizada por Murilo Rocha Seabra, Doutor em Filosofia pela La Trobe University, Melbourne-Austrália à Lúcio Vasconcellos de Verçoza, Doutor em Sociologia pela Universidade Federal de São Carlos (UFSCar) e professor da Universidade Federal de Alagoas (UFAL)-Brasil, realizada por e-mail (murilorseabra@gmail.com; luciovercoza@yahoo.com.br) entre os dias 23 de Setembro e 22 de Dezembro de 2018, com o objectivo de partilhar diversas experiências sobre a importância de se combater o racismo e o sexismo na academia, discute-se igualmente a ascensão do pós-estruturalismo e a derrocada do marxismo durante a Guerra Fria e, finalmente, analisa-se o papel da Filosofia na actual conjuntura política brasileira. 
O décimo primeiro é uma resenha do livro intitulado "Julius Nyerere. Africa's titan on a global stage. Perspectives from Arusha to Obama. North Carolina: Carolina Academic Press. 390 p", da autoria de Ali Mazrui e Lindah Mhando, publicado em 2013, onde é possível compreender o contributo para o entendimento das questões africanas contemporâneas. Nesta resenha, Ermelinda Liberato, Doutorada em Estudos Africanos e investigadora do Instituto Superior de Ciências da Comunicação (ISUCIC), Luanda - Angola, procura ressaltar a mais valia da obra, ao permitir revisitar, num mesmo documento, temáticas-chave das ciências sociais, como a pobreza, exclusão social, desigualdades (nas suas múltiplas dimensões), o peso e importância do sector informal, desenvolvimento, corrupção, exploração, migrações, demografia, liberalização, o papel e posição social das mulheres, as "lideranças africanas" (p. 138), as elites "expostas à tentação" (p. 128), o nepotismo, entre outras, mostrando assim o domínio dos autores sobre as questões que preocupam o continente africano.

Como se pode observar, a Universidade Óscar Ribas nos últimos cinco anos, tem-se caracterizado por mostrar um significativo interesse no que tange à valorização dos processos de produção e gestão do conhecimento gerado pelos seus próprios investigadores, em consonância com os seus parceiros internacionais, que têm desempenhado um papel crucial na solidificação da sua visão sobre ciência, tecnológica e inovação. É neste enquadramento que o Conselho Editorial da revista SAPIENTIAE, agradece e incentiva a comunidade científica a revisar os artigos publicados, assim como a submeter novas proposta para a possível publicação em futuras edições.

$\mathrm{Na}$ expectativa de retoma de contacto com novos resultados, a partir de Janeiro próximo, o Conselho Editorial aproveita a ocasião de publicação do último volume de 2020, para desejar à comunidade científica nacional e internacional, um próspero 2021. 